Página inicial: 479 - Página final: 494

TIPO DE ARTÍCULO: de Investigación

\title{
ENTRE VECINOS: RETOS DE LA JUSTICIA TRANSICIONAL A NIVEL LOCAL. EL CASO DE LA SIERRA DE LA MACARENA, COLOMBIA. ${ }^{2}$
}

\author{
BETWEEN NEIGHBORS: CHALLENGES IN THE LOCAL TRANSITIONAL JUSTICE. THE CASE OF THE "LA \\ SIERRA DE LA MACARENA," COLOMBIA.
}

RECIBIDO: ENERO 2015 REVISADO: ABRIL 2015 ACEPTADO: 2 DE MAYO DE 2015

Por: Keren Marin González ${ }^{1}$

\section{RESUMEN:}

El actual proceso de paz entre el Gobierno Colombiano y las FARC- EP en la Habana ha reavivado el debate en torno a los límites y alcances de la justicia transicional. Fenómenos como la victimización horizontal, consecuencia de la participación indirecta de los civiles en el conflicto, plantea una serie de retos para el modelo de justicia transicional que se defina en la mesa; en particular cómo proceder cuando la violencia ha sido utilizada entre vecinos. Este artículo se centra en esta tensión y para ello presenta una caracterización de los límites de la justicia transicional y analiza los contextos de oportunidad donde la victimización horizontal ha tenido lugar en una región colombiana fuertemente afectada por el conflicto armado, la Sierra de La Macarena. El artículo concluye con la formulación de una hipótesis orientada a proponer una posible alternativa para superar la violencia horizontal en el post conflicto: la posible complementariedad entre los mecanismos de transición y las experiencias locales de justicia comunitaria.

\section{PALABRAS CLAVE:}

Justicia transicional, Victimización horizontal, Posconflicto, Pluralismo jurídico, Conflicto Colombiano.

\begin{abstract}
.
The current peace process between the Colombian Government and FARC - EP in Havana has rekindled the debate over the limits and scope of transitional justice. Phenomena such as horizontal victimization, result of the indirect participation of civilians in the conflict, poses a number of challenges for the transitional justice model, which is defined at the table; in particular how to proceed when violence has been used among neighbors. This article focuses on this tension and, for that, this presents a description of the boundaries of transitional justice and discusses the contexts of opportunity where the horizontal victimization has taken place in a Colombian region strongly affected by the armed conflict, la Sierra de La Macarena. The article concludes with the formulation of a hypothesis aimed at proposing a possible alternative in order to overcome the horizontal violence in the post conflict:, which is the possible complementarity between transitional mechanisms and the local experiences of community justice.
\end{abstract}

\section{KEY WORDS:}

Transitional pluralism, horizontal victimization, Post-conflict, legal pluralism, Colombian conflict.

${ }^{1}$ Politóloga, joven investigadora Universidad de Antioquia. Medellín, Colombia. Contacto: keren.marin@udea.edu.co 


\section{Introducción.}

Distintos procesos de victimización en contextos de conflicto armado han sido comprendidos bajo una clásica perspectiva que reconoce la figura de víctima en los civiles desprevenidos y los victimarios bajo la figura del estado o en grupos insurgentes. Esta perspectiva, según Alan Arias (2012), corresponde con las nociones tradicionales de victimización que comprenden la relación entre víctima y victimario a partir de dos dimensiones: víctima como cuerpo sufriente visible (Sacrificialidad) y sujeto pasivo de un delito tipificado (Juridicismo) y victimario como sujeto que incurre en la violación de los Derechos Humanos.

Dicha interpretación ha consolidado una perspectiva vertical de victimización (Orozco I. , 2005), en la cual los roles de víctima y victimario resultan claros y estrictos en su dicotomía pues se parte del presupuesto de que la violencia tiene un origen claro (Fuerzas MilitaresGrupos insurgentes) y un destino concreto (la población civil). Sin embargo, asumir a priori el carácter pasivo de los civiles en el conflicto, es desconocer el carácter complejo de la violencia política y de los escenarios de oportunidad en donde esta toma lugar (Kalyvas S. , 2004). Al respecto, basta señalar como la violencia armada puede ser empleada por los civiles como recurso de mediación para tramitar conflictos comunitarios, pues en las comunidades -que se encuentran en zona de guerra- se generan incentivos para que los individuos hagan uso privado de la violencia mediante la politización de la vida privada. (Cubides, 2008) (Kalyvas S. , 2010) (Ortiz, 2001). ¿Cómo entender, pues, esos escenarios sociales en donde la población civil puede asumir de manera paulatina el rol de víctima y victimario? ¿Cuáles son los alcances y limitaciones de la Justicia Transicional para tratar este fenómeno?.

El propósito de mi artículo consiste en el análisis de esta serie de problemas a partir de un estudio de caso que realizo en la Sierra de la Macarena, donde he tenido tres temporadas de trabajo de campo en zonas rurales de la región desde el año 2013. El eje central del articulo gira en torno a la inspección de los límites y retos que le esperan a la justicia transicional en escenarios donde el ejercicio indirecto de la violencia impide definir con claridad quién es culpable y quién es inocente.

Dada la urgencia que este tema supone para el país en el escenario de transición tras la posible firma de los acuerdos de la Habana entre el gobierno nacional y la guerrilla de las Farc-Ep, en la sección final del artículo propongo que los procesos horizontales de victimización (sustentándome en el trabajo de campo que realizo desde 2013 en la Sierra de la Macarena) bien pueden ser tratados a partir de una posible complementariedad entre la justicia transicional y las prácticas jurídicas locales.

\section{"El pueblo es a la guerrilla como el agua al pez".}

Stathis Kalyvas (2010) ha caracterizado los conflictos internos destacando su carácter irregular, el cual se expresa -entre otras circunstancias- en la asimetría militar existente entre los actores enfrentados (Fuerzas militares- grupos rebeldes) y en la carencia de enfrentamientos militares directos a gran escala. Este carácter irregular, -contrario al carácter convencional de las guerras interestatales según Kalyvas (2010)- demanda el uso de estrategias no convencionales de guerra que permitan los combates indirectos y de bajo nivel.

Para el despliegue de mecanismos de guerra irregular -como milicias, informantes, contrainteligencia, colaboradores forzados etc- los actores enfrentados (Fuerzas Militares y Grupos insurgentes) buscan disputarse la soberanía a lo largo del territorio nacional y establecer zonas de control y de influencia que les permitan movilizar la población civil en 
el conflicto, pues es mediante el control del territorio en que las estrategias irregulares de guerra pueden ser desplegadas (Cubides, 2008) (Franco, 2001).

En este escenario, el campo de batalla en las guerras irregulares no se restringe a la contienda militar si no que se despliega mediante una lucha silenciosa que también se abre paso a través de la gente. Una guerra así viene a ser "como un hombre que tiene que golpear al otro través del cuerpo del árbitro" (Testimonio de un campesino Chipriota retomado por Kalyvas, 2010, p 137). Este testimonio ilustra bien el papel central que adquiere la población civil en medio del conflicto, pues es mediante su colaboración que los actores enfrentados (tanto guerrillas, como ejércitos oficiales) obtienen, entre otras cosas, información valiosa que resulta determinante para desequilibrar al enemigo sin necesidad de emplear la fuerza.

Esta colaboración de los civiles con los grupos armados (estatales o insurgentes) puede ser voluntaria o de facto. La colaboración voluntaria viene precedida, en ocasiones, por un trabajo político previo del grupo armado en la zona. Ejemplo de ello es la labor política d e la guerrilla en la Sierra de la Macarena, labor que se expresa en el cuidado y control del medio ambiente (regulación de la caza, la pesca, la tala de bosques etc), en la regulación de la vida social (intervención y arreglo de problemas entre vecinos, vigilancia y oferta de seguridad en la zona y elaboración de manuales de convivencia) o en la realización de proyectos conjuntos con las comunidades como la construcción y mantenimiento de carreteras. Por su parte, el trabajo político de las Fuerzas Militares se expresa en el ofrecimiento de servicios (salud, educación, deportes, infraestructura) a cambio de entrega de información y solidaridad de la población civil con el proyecto oficial.

Esta intervención de los grupos armados en la vida diaria construye espacios de participación civil en el conflicto que permiten el despliegue de estrategias de guerra irregular como las milicias o las redes de cooperantes. Sin embargo, la población civil no solo sirve a los grupos armados mediante la colaboración -voluntaria o de facto-, sino que los grupos armados pueden llegar a servirles a los civiles para tramitar sus conflictos privados mediante la violencia que ejercen.

Ejemplo de ello es la victimización horizontal, escenario en el cual la dialéctica victima/ victimario se estructura también a través de otras figuras distintas y complementarias como del vengador o la del "sobreviviente", lo que dificulta establecer quiénes son los "buenos" y quiénes son los "malos" pues se presenta un mayor involucramiento y movilización de la población civil en el conflicto. (Orozco I. , 2005).

Para ilustrar estos procesos de victimización horizontal, en la siguiente sección expondré tres casos en los cuales los civiles hicieron uso tanto de los mecanismos de denuncia de la guerrilla como del programa de desmovilización del Gobierno Nacional para conducir de manera indirecta la violencia ejercida por los grupos armados o acceder a beneficios económicos. Las historias que expongo son producto de un (pre) trabajo de campo realizado en la Sierra de la Macarena durante Diciembre 2013- Enero 2014 y Junio 2014-Julio 2014.

\section{La región.}

La Sierra de la Macarena está ubicada entre los departamentos del Meta y Caquetá y es punto de encuentro de los ecosistemas andino, amazónico y orinocense (Espinosa N. , "A la otra orilla del río. La relación entre los campesinos y la guerrilla en la sierra de La Macarena” Tesis de Pregrado, 2003) (Véase mapa 01). La construcción social de La Sierra de la Macarena como territorio inició con las colonizaciones campesinas durante el periodo 
de "la violencia", la formación de las Guerrillas Liberales del Llano entre 1949-1964 y la posterior fundación de las FARC a orillas del río duda en 1964 (Aguilera, 2014) (Espinosa N. , El justo comunitario, las leyes y la justicia en una región con fuerte presencia del conflicto armado. Etnografia del pluralismo jurídico en la Sierra de La Macarena., 2010).

Mapa 01.

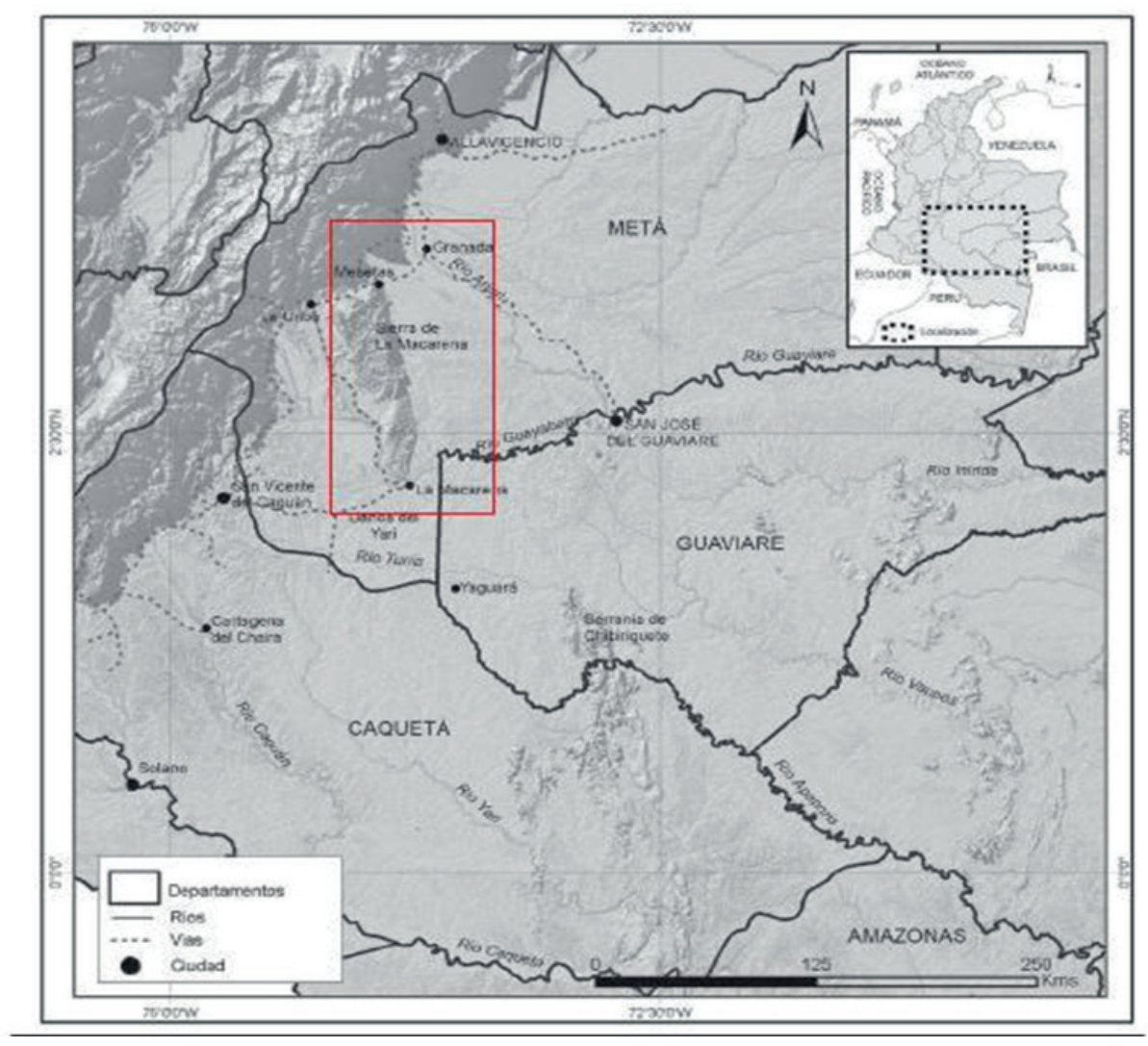

Ubicación de la Sierra de la Macarena. Fuente Cartográfica: Espinosa (2010)

Al ser zona de colonización -espontánea y dirigida- la composición étnica y cultural de la Macarena es diversa. Campesinos de Antioquia, Boyacá, Caquetá, Cundinamarca, Santander, Tolima y Valle entre otras regiones del país, llegaron a la zona en búsqueda de tierras o riqueza. Según Espinosa (2003), pueden distinguirse tres olas de colonización en la Macarena: a. La colonización de campesinos expulsados por la violencia hacia los márgenes del país en el periodo de 1953-1960; b. la colonización dirigida por el Estado Colombiano entre 1961-1970 y c. la ola de colonización producto de la bonanza y auge de la coca entre 1980-1984.

Durante estos periodos, la economía de la Macarena ha oscilado entre bonanzas económicas transitorias como la pesca, la madera y la marihuana y economías permanentes y semiextractivas como la coca y la ganadería. En este escenario regional, la guerrilla ha desempeñado un papel fundamental en la construcción de la región, pues al ser una zona marginal y de colonización, el proyecto insurgente ha encontrado un escenario en el cual experimentar y definir su proyecto político y militar.

Como epicentro del conflicto armado en Colombia, la región ha sido escenario de dos negociaciones de las FARC con el Gobierno Nacional: Los diálogos en la Uribe, Meta 
durante el periodo 1984-1987 y zona de distención entre 1999-2002, periodo en el cual se implementó el Plan Colombia en el 2000 y posterior al fracasado dialogo de paz en el Caguán, ofensivas militares mediante planes y politicas como el Plan Patriota en el 2003, la Política de Seguridad Democrática entre 2002-2010, y el Plan Nacional de Consolidación Territorial 2009-2014.

Toda esta historia regional en medio de la guerra ha determinado una relación tanto instrumental como ideológica entre los campesinos de la región y el grupo guerrillero (cfr. Aguilera, 2014; Espinosa, 2003 -2010), en donde el carácter íntimo y vivencial del conflicto armado se manifiesta en la instrumentalización de la violencia organizada (política o no) a manos de civiles para negociar conflictos privados (fenómeno analizado por Kalyvas, 2010).

\section{Los casos.}

\section{Todos contra el Pollo}

El 10 de noviembre de 2002 el Pollo, presidente de la Junta de Acción Comunal de su comunidad, padre de dos hijas y esposo de Doña Soledad, fue asesinado por la guerrilla de las FARC-EP en la vereda el Socorro de la Sierra de la Macarena. Los guerrilleros del Séptimo Frente justificaron el hecho ante familiares y vecinos alegando que el Pollo era un 'sapo' del ejército. Esta versión de los hechos fue aceptada por algunos miembros de la comunidad como cierta, pues es común en la región considerar que si a alguien lo matan "es por algo" (Espinosa N. , Política de vida y muerte. Etnografia de la vida diaria en la Macarena, 2010).

Ante el suceso, Doña soledad y sus hijas abandonaron la región por miedo a represalias por parte del grupo guerrillero. Sin embargo, con el transcurrir del tiempo, la gente de la vereda descubrió que la muerte del pollo fue producto de "denuncias" y "cuentos" que los Echandía -vecinos con quienes el Pollo guardaba viejas rencillas- llevaron a la guerrilla. Ante estos rumores y en vista de que había nuevas versiones sobre los hechos, los líderes comunitarios realizaron gestiones para asegurarse de que la guerrilla no tuviese cuentas pendientes con la familia de El Pollo. Al cerciorasen de que no había problema alguno, Doña soledad y sus hijas regresaron a la vereda. De igual forma y con el tiempo, la gente de la región - tras contrastar varios rumores que circulaban en la vereda- acusó a los Echandía de entregar información falsa a la guerrilla. Semejante acusación se vería demostrada cuando a los pocos días los Echandía -aun sin ser guerrilleros o milicianos-se desmovilizaron, marchándose de la región. Esto permitió a la gente de la vereda comprobar que el Pollo no había sido sapo del ejército sino una víctima más de "las malas lenguas" de sus vecinos. (Remedios, 2014)

\section{La huésped.}

Corría el año 2004 cuando un escándalo sacudió a la vereda del Cocuyo. Mechas, una joven de 15 años y estudiante del internado de la vereda, resultó embarazada de un jornalero de la región apodado el Ovejo. Ante la dificultad para permanecer internada en su estado de gestación, Doña Pilar y Don Guillermo -vecinos del internado- le ofrecieron a Mechas su hogar y la acogieron como su huésped, pues de esa manera ella podría continuar con sus estudios. Mechas aceptó la propuesta y se trasladó a vivir con Doña Pilar y Don Guillermo, con quienes ella y el Ovejo entablaron una estrecha relación.

Sin embargo, un día Mechas -al salir antes de lo previsto de la escuela- descubrió que Doña Pilar y el Ovejo tenían una relación sentimental. Ante el suceso, Mechas decidió cobrar 
venganza contra Doña Pilar, para lo cual se dirigió a una unidad militar cercana que por esos días patrullaba por la vereda y se desmovilizó, arguyendo pertenecer a las milicias del Frente 40 de las FARC. En su declaración, acusó a Doña Pilar de ser miliciana de las FARC e indico quien fue ella quien la reclutó para prestar apoyo a la guerrilla. Ante tales denuncias, el ejército capturó a Doña Pilar, quien tuvo que enfrentar cargos por rebelión. Tras dos años de prisión y ante la falta de pruebas concluyentes, Doña Pilar recobró su libertad. (Aureliano, 2014)

\section{La escuela guerrillera}

Eugenia era según sus vecinos, una mujer harto trabajadora a quien sin embargo las oportunidades laborales le eran escasas. Era madre soltera de dos niños y trabajaba como cocinera en fincas de la vereda Villa Gallina. Su situación económica empezó a complicarse cuando por motivos de salud no pudo volver a trabajar. Ante la situación, Eugenia vio en el Programa de Desmovilización, una opción viable para solucionar su situación económica. Sin embargo, para poder acceder al programa debía de entregar información sobre la guerrilla o sus colaboradores y Eugenia que no deseaba implicar directamente a nadie, señalo falsamente, que en la escuela de la vereda la guerrilla de las FARC reclutaba y entrenaba militarmente a niños de la región.

Las consecuencias de su declaración no fueron previstas por Eugenia. El ejército detuvo durante un tiempo el funcionamiento de la escuela afectando alrededor de 80 niños que allí estudiaban, el rector pasó a ser investigado por la Fiscalía General de la Nación y los pocos recursos destinados al claustro escolar fueron suspendidos. Por fortuna, la Junta de Acción Comunal de la vereda Villa Gallina se organizó para hacerse cargo de las falsas acusaciones y logró poner nuevamente en funcionamiento la escuela de la vereda. Eugenia abandonó la región con sus hijos tras desmovilizarse y fue sentenciada por la guerrilla, quien le advirtió que en caso de querer regresar a la región su vida pagaria las consecuencias (Martina, 2014)

\section{Victimización horizontal y contextos de oportunidad.}

Historias como la del Pollo o la de Mechas, permiten ilustrar como los civiles pueden llegar a invertir la lógica externa (es ejercida por bandos armados) y vertical (la relación víctimavictimario es clara) de la violencia política cuando la emplean para tramitar conflictos y querellas comunitarias. Sin embargo, cabe aclarar que la victimización horizontal no se circunscribe únicamente a la venganza o a la resolución violenta de los conflictos como iniciativa comunitaria, sino que también puede ser agenciada desde los bandos en conflicto en el marco de sus políticas, bien sean de control politico local desde la guerrilla, o de iniciativas contrainsurgentes desde el estado. Algunos de los impactos sociales de la instrumentalización de los civiles puede observarse en historias como la de Eugenia.

En este caso es posible establecer uno de los desenlaces que la política de desmovilización ha tenido entre la población. Desmovilizarse ha significado para gentes de la región -vinculadas a la insurgencia, o no- la posibilidad de obtener una serie de derechos que dada la marginalidad económica y social de la región, en La Macarena son considerados privilegios: acceso a educación propia y para hijos e hijas, servicios de salud, apoyo a iniciativas productivas, atención psicosocial, subsidios económicos, entre otros (Agencia Colombiana para la Reintegración (ACR), 2010). 


\section{Imagen 1.}

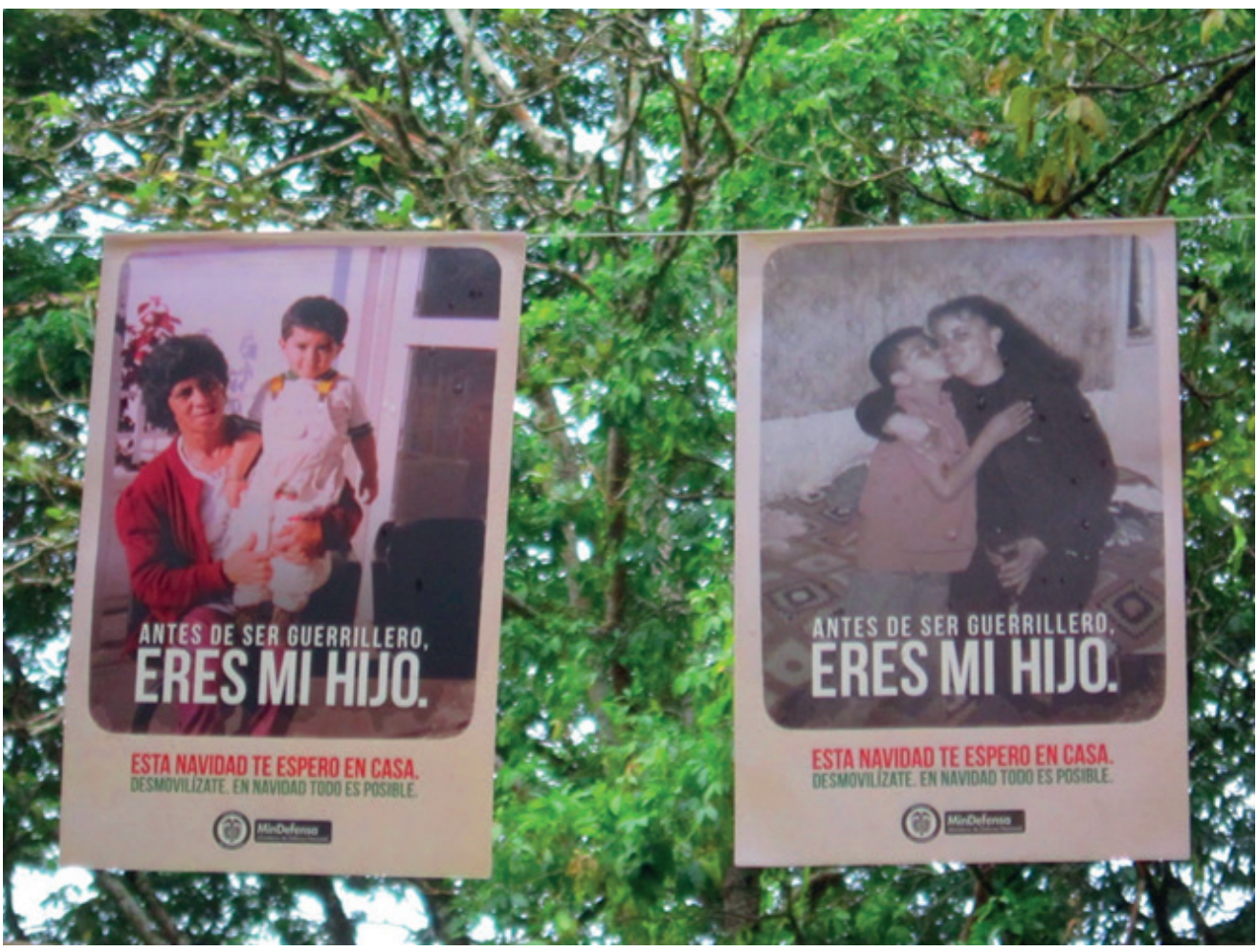

Propaganda oficial del programa de desmovilización. San Vicente del Caguan. Autoría propia.

Estos relatos no dan cuenta solo de decisiones subjetivas (desmovilizarse-denunciar) o de quiebres comunitarios (desconfianza y hostilidad entre vecinos) sino de un contexto socio politico que plantea a los sujetos una serie de alternativas - violentas- para tramitar sus conflictos o agenciar sus decisiones. Para comprender los escenarios que permiten la victimización horizontal, planteo el concepto de contexto de oportunidad el cual me permite identificar y comprender los múltiples incentivos que desde diversos niveles (internacional, nacional, local) y actores (Fuerzas Militares, Grupos Insurgentes) posibilitan el uso indirecto de la violencia a manos de civiles.

El contexto de oportunidad es un espacio social y político en donde la superposición del conflicto central (la guerra) y los conflictos locales (problemas comunitarios) permite a los civiles politizar su vida privada y hacer uso privado de la violencia. Esta superposición entre el nivel central y local, esta mediada por las interpretaciones del conflicto y las estrategias de guerra desplegadas por los bandos enfrentados, los cuales al hacer de la colaboración civil una estrategia indispensable en la contienda, producen incentivos para que los civiles recurran a la violencia como medio de resolución de conflictos.

\section{Contextos de oportunidad en el conflicto colombiano.}

La guerra no es solo un enfrentamiento militar en el campo de batalla sino un enfrentamiento simbólico respecto a cómo y quienes interpretan el conflicto. En este sentido, la interpretación del conflicto colombiano varía según los actores (Gobierno Nacional, Fuerzas Militares, 
Grupos insurgentes, sociedad civil) y según el nivel de interpretación (internacional, nacional, local).

Al respecto, puede afirmarse que si bien dentro del contexto de oportunidad hay incentivos - para la instrumentalización civil de la violencia- que provienen desde actores armados como el ejército o la guerrilla (bien sea la escasa verificación de la información, la obtención de beneficios económicos por entrega de datos o la construcción del rumor y el chisme como fuentes de veracidad), estos incentivos están determinados simultáneamente por políticas a nivel nacional e internacional que comprenden de un modo particular el conflicto y actúan sobre este según su interpretación.

En el trámite del conflicto colombiano, la cual invalida mediante la noción de terrorismo y la teoría económica del conflicto, las características sociales y políticas subyacentes al conflicto. Estas interpretaciones -que surgen a nivel internacional pero tienen impacto directo en el manejo nacional del conflicto- transforman las estrategias locales de guerra y seguridad tanto de fuerzas armadas legales como insurgentes, pues.

las formas específicas que asume el uso de la fuerza no son fortuitas, sino que tienen correspondencias significativas con las formas de organización del poder político, las representaciones sociales y los valores vigentes que lo hacen aceptable (Calveiro, 2012, p 14).

Una de estas interpretaciones, la del gobierno norteamericano y su "guerra contra las drogas" y "guerra contra el terror", ha definido que las Fuerzas Armadas asuman sus funciones constitucionales en el marco de una lucha antiterrorista y antinarcóticos bajo la implementación del Plan Colombia, el Plan Patriota y la Política de Defensa y Seguridad Democrática. Estas políticas contemplan la corresponsabilidad cívico-militar como estrategia óptima para la lucha antiterrorista y la consolidación de la seguridad en zonas deprimidas y de conflicto.

Para la puesta en marcha de la corresponsabilidad civico-militar, se crearon programas como la red de cooperantes, la red de informantes y el Programa de desmovilización, los cuales mediante la "promoción de la cooperación voluntaria y patriótica de los ciudadanos" buscan contribuir a la prevención del terrorismo y la delincuencia. Lo anterior porque, según la Política de Defensa y Seguridad Democrática, pues la seguridad no se alcanza únicamente con los esfuerzos de la Fuerza Pública sino con la cooperación solidaria y el compromiso de toda la sociedad (Ministerio de Defensa Nacional, 2003).

Sin embargo, la cooperación civil se circunscribió paulatinamente a incentivos de tipo económico -como el programa de recompensas- o de acceso a los recursos disponibles del estado en materia de salud, educación y subsidios económicos, lo que produjo un aumento en la entrega de información falsa así como un incremento en el número de civiles desmovilizados que no pertenecían ni colaboraban con grupos insurgentes.

Como podrá verse en el siguiente testimonio, la estigmatización que existe en nuestro país sobre las denominadas "zonas rojas" permiten suponer, desde discursos y practicas oficiales, que todos sus habitantes son guerrilleros o cómplices del terrorismo. Estos lugares comunes permiten que las denuncias de desmovilizados partan de una premisa falsa de supuesta veracidad: no hace falta verificar la información obtenida por un desmovilizado de La Macarena, porque seguramente las personas del lugar han de ser guerrilleras. 
Al respecto, Emérito, campesino proveniente de Arauca y residente en la Macarena, me comentó que.

"el solo vivir en una zona roja como esta otorga inmediatamente el rotulo de guerrillero, pues se piensa que cualquiera que viva por aquí es miliciano, colaborador o simpatizante de la guerrilla...y no solo lo piensa el ejército, también lo piensa la gente de afuera y hasta los otros grupos armados... si no pregúnteme a mí que un día fui a Bahía Solano y los paramilitares me iban a pelar por el simple hecho de venir de la Macarena" (Emerito, 2013).

Esta estigmatización promueve en civiles el uso de la denuncia bien sea para obtener beneficios económicos o tramitar sus conflictos, pues en la medida en que se parte de un concepto a priori -relacionar inmediatamente las zonas rojas y sus habitantes con la guerrilla- se hace "innecesaria" la validación de la información por parte de quienes la reciben, en este caso las Fuerzas Militares.

\section{Imagen 2.}

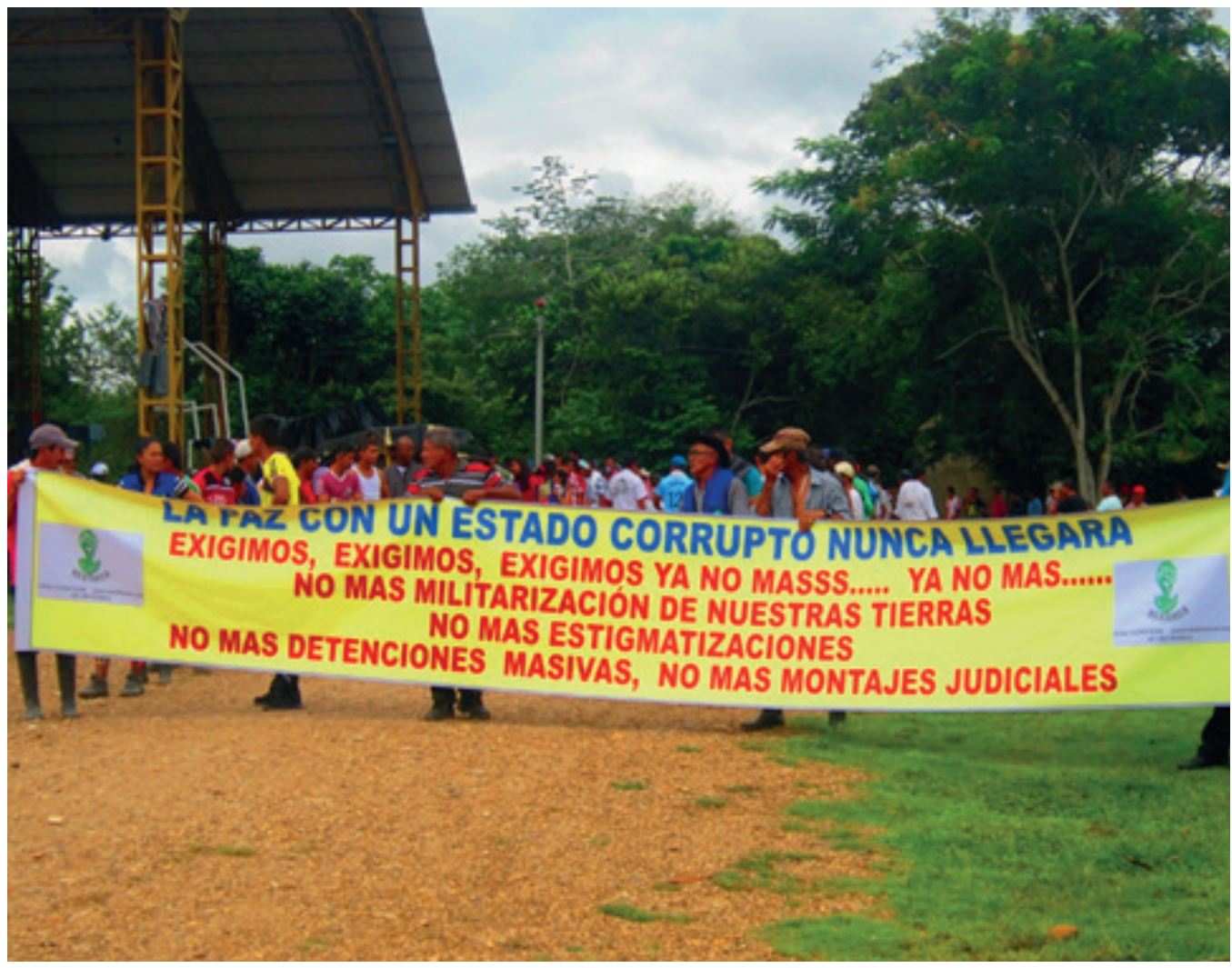

Movilización permanente por los DDHH. La Macarena, Noviembre de 2014

Otros contextos de oportunidad para el uso indirecto de la violencia se establecen a partir de las estrategias de guerra empleadas por la guerrilla frente a las ofensivas de las Fuerzas Militares. El comportamiento de las FARC en el periodo de consolidación del Plan Patriota (que desplegó alrededor de 27.000 hombres en el Caquetá, sur del Meta y Guaviare) y la Política de Defensa y Seguridad Democrática, osciló entre el repliegue táctico y la adopción de la guerra de guerrillas como estrategia de combate (Echandia \& Bechara, 2006). Durante este periodo de tiempo, algunas zonas de repliegue consolidadas por las FARC durante el despeje, transitaron lentamente a ser zonas en disputa entre el grupo guerrillero y los 
militares (Aguilera, 2014) En este escenario, la participación de la población civil en el apoyo de la fuerza insurgente se hizo más necesaria que en tiempos anteriores, pues la vulnerabilidad militar de la guerrilla hizo del apoyo popular parte indispensable en su búsqueda por retomar el control de los territorios y las poblaciones.

Sin embargo, el despliegue de la corresponsabilidad civico-militar como estrategia contrainsurgente (violatoria del $\mathrm{DIH}$, en tanto desdibuja el criterio de distinción entre civiles y combatientes), fue capaz de debilitar la relación guerrilla-civiles. De alli que la desconfianza de los insurgentes hacia la población civil y el uso indiscriminado de la justicia ejemplarizante como instrumento de disciplinamiento (Aguilera, 2014) se incrementara en La Macarena.

En este escenario donde la desconfianza se instituye como norma, la denuncia y las redes de información se convierten en instrumento de contención a la estrategia contrainsurgente en una doble vía: transforman los civiles en "aliados" y los hacen simultáneamente participes de la guerra, bien sea como informantes o colaboradores. Ejemplo de ello, son las milicias, red de apoyo civil que mediante la entrega de información permanente a la guerrilla busca facilitar tanto su presencia en los territorios como su control sobre las poblaciones.

Esta participación de los civiles - voluntaria o de facto- en la contienda, crea espacios propicios para el uso comunitario de la violencia armada y por ende para la victimizacion horizontal, cuestión que repercute tanto en la confianza comunitaria como en el imaginario colectivo del sentido de solidaridad: las narrativas sociales dan cuenta del uso de la violencia como recurso legítimo de mediación social, práctica que se agudiza cuando ejército como guerrilla invierten la presunción inicial de inocencia en culpabilidad, es decir, se es desde el inicio enemigo y sujeto de sospecha.

\section{Agenda para el postconflicto: pluralismo jurídico como alternativa para tratar la victimización horizontal.}

La justicia transicional según Rodrigo Uprimny (2005) se define como la serie de "procesos a través de los cuales se realizan transformaciones radicales de un orden social y político, bien sea por el paso de un régimen dictatorial a uno democrático, bien por la finalización de un conflicto interno armado y la consecución de la paz" (Uprimny, 2005, p 2). Sin embargo, el concepto de justicia transicional varía en relación con el carácter de los conflictos en que interviene (dictadura, conflicto interno, guerra interestatal, totalitarismos etc.) dada la necesidad de adaptarse a las diferentes y variadas circunstancias en las que tiene que operar (Gómez F. , 2010) (Lecombe, 2010).

Aún más: la maleabilidad de la justicia transicional se reduce cuando trata de comprender distintos procesos de victimización, pues al ser legado jurídico y moral de Núremberg plantea, según Arias (2012) un concepto restrictivo de victima a partir de la figura del delito, es decir: se es víctima siempre y cuando haya una infracción sancionada por el derecho positivo. Esta noción de víctima, predominantemente jurídica, limita el uso de la justicia transicional a escenarios verticales de victimización en los cuales la dialéctica víctima -victimario no admite superposición (Orozco I. , 2005), tendencia que es reforzada por la incapacidad de los procesos jurídicos tradicionales para develar las fracturas sociales que están detrás de conflictos de carácter político. El derecho oficial, así sea en contextos de transición, solo toma una parte limitada de la realidad social al excluir de su normatividad lo que le excede (González, 2005) (Giraldo, 1997). 
En este sentido, el desafio de la justicia transicional apunta a la ampliación de su campo de interpretación más allá del carácter restrictivo del derecho oficial, pues la violencia más que un fenómeno uniforme se manifiesta de forma multidimensional y compleja. Esta situación demanda, más allá de la sanción penal y retributiva, herramientas que posibiliten la reconciliación y el perdón, en particular en casos de victimización horizontal.

Dado que la victimización horizontal encuentra limitaciones para su tratamiento mediante el campo del derecho positivo, una de las alternativas posibles para su resolución bien puede encontrarse en instancias y mecanismos propios del pluralismo jurídico, en particular en instancias de justicia comunitaria como las existentes en La Macarena.

El concepto de Pluralismo Jurídico, según Santos y García (2001), parte del reconocimiento de que en las sociedades contemporáneas existen multiplicidad de prácticas jurídicas las cuales buscan dar solución a situaciones problemas por vías alternativas más allá del campo oficial del derecho. Estas prácticas jurídicas alternativas tienen su razón de ser, según Edgar Ardila (2002), en la ineficacia de la norma legal como orientadora de las relaciones sociales y la crisis de la administración de justicia para atender la conflictividad. El derecho oficial, por lo tanto y ante tal panorama, es insuficiente para comprender las múltiples realidades, por lo que emergen prácticas jurídicas alternas o alternativas a él.

En este sentido, considero que el pluralismo jurídico puede ser una opción viable para tramitar escenarios de victimización horizontal. Este tema traza mi actual agenda de investigación y se sustenta, no solo en el trabajo que desarrollo en La Macarena sino en aportes como el de Giraldo (1997), quien plantea que la incorporación de mecanismos alternativos al derecho positivo buscan dar solución de los problemas de la gente a escala real y no bajo el aspecto limitado consagrado en el ordenamiento jurídico. El equilibrio entre órdenes legales oficiales y alternativos, dice Giraldo, facilita la conciliación y la reconstrucción de los lazos comunitarios afectados por la violencia.

Como recién he mencionado, la pertinencia del pluralismo jurídico para atender casos de victimización horizontal en un escenario de post conflicto, le encuentro en el papel que ha jugado la justicia local de la Macarena en la construcción de prácticas de resistencia e identidades comunitarias. Este tipo de justicia se expresa en las Juntas de Acción Comunal (JAC) las cuales buscan el trámite y regulación de los conflictos de manera pacífica y conciliadora a partir del trabajo de los Comités de Conciliación. El siguiente testimonio da cuenta de ello.

Don Ernesto, presidente de la JAC en la vereda Santa María, dio cuenta de que las JAC nacieron a mediados de los noventa en la región del Guayabero Alto como respuesta comunitaria al abandono estatal y la intervención guerrillera (otras JAC fueron creadas en La Macarena conforme las veredas fueron fundándose, bien sea en los años 70, 80 o a lo largo de la última década). Las JAC buscan mediante su labor impulsar la autonomía y la unión de la comunidad. Están formadas por la directiva (presidente, vicepresidente, tesorero, secretario), cinco comités de trabajo (obras, salud, educación, deporte, medio ambiente), la figura de la fiscalía (fiscal titular, fiscal suplente), El Comité de Convivencia y Conciliación y la Asamblea (conformada por todos los afiliados a la JAC).

El Comité de Convivencia y Conciliación, desempeña un papel fundamental en el fortalecimiento de las confianzas comunitarias pues integra líderes comunitarios elegidos a partir de deliberaciones realizadas por los habitantes de una vereda. El Comité está conformado por tres personas: el presidente de la junta y dos miembros de la JAC que son elegidos por la comunidad en base a cualidades como la imparcialidad, la honestidad y la 
transparencia. Cuando se presenta un conflicto, el Comité visita a las dos partes y escucha la versión de los hechos, para después deliberar sobre cómo actuar. Normalmente se llega a la conciliación, pero en caso de que las partes no deseen conciliar se fijan multas o días de trabajo.

Detrás del funcionamiento del comité, dice Espinosa (2010).

existe una concepción de lo justo que da orden a la vida social y jurídica de una región, una noción de la justicia que autoriza o no esas transformaciones, que legitima las normas, las instancias y los procedimientos para la resolución de conflictos (Espinosa, 2010, p 4).

Esta modalidad de justicia es ante todo constructiva, pues en lugar de obrar por medio de la vía penal que establece cargos de inocencia y culpabilidad, busca un mecanismo que permita negociar el conflicto e impulsar simultáneamente mejores condiciones en la convivencia.

Don Ernesto me contó que gracias a la junta y los comités, las comunidades han logrado impulsar iniciativas que benefician el desarrollo social y económico de la región y tramitar -sin intervención de la guerrilla- los problemas que surgen en el seno de las comunidades. Relató que, en principio,

“...nos unimos para hacer las carreteras, pero con el tiempo también empezamos a ocuparnos del medio ambiente, los Derechos Humanos y hasta de los problemas de la gente. Ya no necesitamos de los guerros pa' que nos arreglen los líos ni estamos a la espera de la ayuda del estado. Ahora arreglamos nuestros propios problemas y salimos a exigir nuestros derechos". (Ernesto, 2014).

Según Espinosa (2009), las JAC se han constituido como un mecanismo "que tiene el poder y la legitimidad para ser garante y rector de la organización social regional" (Espinosa, 2009:138), lo que ha permitido -según los pobladores- afianzar los lazos sociales entre los miembros de la comunidad y ganar espacios autónomos para la resolución de sus conflictos.

En este sentido, considero que bien valdría la pena en un escenario posconflicto, articular los mecanismos del derecho oficial con las prácticas jurídicas alternativas como la justicia local. Esta articulación podría contribuir a "reconciliar no solamente el sufrimiento experimentado sino también el sufrimiento infligido" (Theidon, 2004, p 18). Ello mediante el trámite desde las comunidades hacia las comunidades. Además, la justicia local tiene la capacidad -por su misma escala de aplicación- de entrever las problemáticas que subyacen detrás del conflicto, como las condiciones sociales o económicas que llevaron a la instrumentalización de la violencia.

Tal como lo expresa Don Ernesto "nadie sabe mejor las cosas que pasan aquí y por qué pasan que nosotros mismos" (Ernesto, 2014) En este sentido, la justicia "de afuera" no está preparada para incursionar en escenarios de guerra en donde ante una presencia relativa del estado las comunidades han dado paso a formas alternativas de justicia. Para poder funcionar y tener reconocimiento, cualquier modelo de justicia transicional que se proponga para tramitar los conflictos existentes en las regiones marginales del país, en particular las del piedemonte amazónico, han de recurrir a los mecanismos e instancias alternativas dispuestas por las comunidades campesinas, pues son ellas quienes han regulado históricamente una región en conflicto. 


\section{Conclusiones.}

En este artículo me he propuesto analizar el problema que suponen las formas tradicionales de Justicia Transicional para el trámite de la victimización horizontal. La Sierra de La Macarena en Colombia, como escenario de guerra en donde la población civil ha sido el foco de atención privilegiado tanto desde el estado como de la guerrilla, el uso instrumental de la violencia por los civiles ha sido uno de los procesos más perversos que ha traído consigo el conflicto armado colombiano. A consecuencia de ello, la victimización horizontal es uno de los impactos sociales que con más ha afectado la vida comunitaria.

Ahora bien, como concepto la victimización horizontal permite observar una serie de efectos de la guerra que escapan a los modelos clásicos de justicia transicional, pues la dinámica del conflicto en la región ha reescrito las lógicas tradicionales de víctimas y victimarios. Tal dinámica ha implicado que la forma explícita en que las fuerzas estatales y la insurgencia han buscado involucrar al a población en la confrontación, antes que construir una sociedad civil fiel al estado, o un pueblo convencido de la lucha revolucionaria, han creado o profundizado fracturas comunitarias de solidaridad, liderazgo y convivencia. Es decir, el caso colombiano no solo cuenta con escenas de instrumentalización de la violencia a manos de civiles, sino también de la violación deliberada del criterio de distinción establecido por el DIH por parte del estado y de la guerrilla. Todos estos factores configuran pues las implicaciones de la victimización horizontal.

Como he mostrado en los casos trabajados para el artículo, las fracturas comunitarias existentes en La Macarena han sido creadas o exacerbadas en el marco de una serie de contextos de oportunidades en donde entran en juego los conflictos comunitarios, las políticas del estado, las prácticas guerrilleras y la consecuente lógica resultante de la violencia política. Todos estos factores aunque juegan distintos papeles definen, en consecuencia, los mencionados contextos de oportunidad.

Ahora bien, en un posible escenario de postconflicto tras la firma de los acuerdos en la Habana ¿cómo tramitar las fracturas sociales derivadas de la victimización horizontal? ¿Cómo reconstruir la confianza cívica hacia las instituciones del estado, como fortalecer la legitimidad politica de organizaciones politicas derivadas de la firma de la paz? Tales preguntas han guiado mi ejercicio de investigación, en donde -a la manera de hipótesis- he planteado que una alternativa puede ser la articulación de esfuerzos transaccionales definidos por la mesa de negociaciones, con las prácticas comunitarias de resolución de conflictos.

Las instancias locales de Justicia Comunitaria cuentan con una tradición de varias décadas que les permiten entender y atender los problemas jurídicos locales con lógicas consuetudinarias que permiten el fortalecimiento de los lazos sociales. Tal vez, y esta es una de las preguntas que orientan mi agenda de investigación, las instancias comunitarias resulten escenarios privilegiados para tramitar la victimización horizontal. 


\section{Referencias bibliográficas.}

Agamben, G. (2000). Lo que queda de Auschwitz. El archivo y el testigo. Valencia: Pretextos.

Agencia Colombiana para la Reintegración (ACR). (s.f.). Reintegración. Obtenido de http:/ / www.reintegracion.gov.co/Reintegracion/procesodereintegracion/Paginas/ desmovilizacion.aspx\#.U_Sa_qPeNFk

Aguilera, M. (2014). Contrapoder y justicia guerrillera. Fragmentación politica y orden insurgente en Colombia (1952-2003). Bogotá: IEPRI.

Ardila, E. (2002). Pluralismo jurídico apuntes para el debate. El otro derecho, 49-61.

Arias, A. (2012). Teoría crítica y derechos humanos: hacia un concepto crítico de víctima. Revista critica de ciencias sociales y jurídicas, 36(4), 31-60.

Aureliano. (Junio de 2014). Sierra de la Macarena.

Calveiro, P. (2012). Violencias de Estado. La guerra antiterrorista y la guerra contra el crimen como medios de control global. Buenos Aires: Siglo XXI.

Cubides, F. (2008). "Colombia: las lógicas de la guerra irregular y la resistencia civil”. Polis Revista de la Universidad Bolivariana, 1-16. Recuperado el 22 de Marzo de 2014, de http:// polis.revues.org/3835

Echandia, C., \& Bechara, F. (2006). Conducta de la guerrilla durante el gobierno Uribe Vélez: de las lógicas de control territorial a las lógicas de control estratégico. Análisis politico, 31-54.

Emerito. (Enero de 2013). (K. Marín González, Entrevistador) La Macarena.

Ernesto, D. (Junio de 2014). (K. Marín González, Entrevistador) La Sierra de la Macarena.

Espinosa, N. (2003). "A la otra orilla del río. La relación entre los campesinos y la guerrilla en la sierra de La Macarena” Tesis de Pregrado. Bogotá: Universidad Nacional de Colombia.

Espinosa, N. (2009). El campo jurídico del otro derecho. Elementos para un análisis crítico de la justicia alternativa en una zona de fuerte conflicto armado. Revista Colombiana de Sociología, 133-155.

Espinosa, N. (2010). El justo comunitario, las leyes y la justicia en una región con fuerte presencia del conflicto armado. Etnografia del pluralismo jurídico en la Sierra de La Macarena. Diálogos de derecho y política, 1-26.

Espinosa, N. (2010). Politica de vida y muerte. Etnografia de la vida diaria en la Macarena. Bogotá: Instituto Colombiano de Antropología e Historia ICANH.

Franco, V. (2001). Guerra irregular: Entre la política y el imperativo moral. Estudios políticos, 37-70. 
Giraldo, J. (1997). Los mecanismos alternativos de resolución de conflictos como camino para volver a llenar el derecho de contenido social. En A. Barrios, Conflicto y contexto: resolución alternativa de conflictos y contexto social (págs. 3-16). Bogotá: Instituto ser de investigación.

Gómez, F. (2010). Retos de la justicia transicional en contextos no transicionales: el caso de Colombia. En M. Reed, \& M. Rivera, Transiciones en contienda: disyuntivas de la justicia transicional en Colombia desde la experiencia comparada (págs. 188-2010). Bogotá: Centro Internacional para la Justicia Transicional ICTJ.

Gómez, G. (2013). Justicia transicional desde abajo: un marco teórico constructivista para el análisis de la experiencia colombiana. Revista Coherencia, 45-63.

González, J. (2005). Verdad, justicia, paz y reparación en la mitología penal. A propósito de la ley 975 de 2005. Estudios politicos, 45-63.

Kalyvas, S. (2004). La ontología de la violencia politica: acción e identidad en las guerras civiles. Análisis politico, 51-77.

Kalyvas, S. (2010). La lógica de la violencia en la guerra civil. España: Akal Universitaria.

Leal, F. (2006). La política de seguridad democrática 2002-2006. Análisis político, 3-30.

Lecombe, D. (2010). Una paz conflictiva: luchas epistémicas en torno a la definición de la justicia transicional en Colombia. En M. Reed, \& M. Rivera, Transiciones en contienda: disyuntivas de la justicia transicional en Colombia desde la experiencia comparada (págs. 211-224). Bogotá: Centro Internacional para la Justicia Transicional ICTJ.

Levi, P. (2005). Los hundidos y los salvados. España: El Aleph.

Martina, D. (Junio de 2014). (K. Marín González, Entrevistador) Sierra de la Macarena.

Ministerio de Defensa Nacional. (2003). Política de Defensa y Seguridad Democrática. Bogotá: Presidencia de la República.

Orozco, I. (2002). La postguerra colombiana: divagaciones sobre la venganza, la justicia y la reconciliación. Análisis político, 78-99.

Orozco, I. (2005). Sobre los limites de la conciencia humanitaria. Dilemas de la paz y la justicia en América Latina. Bogotá: Temis-Universidad de Los Andes.

Ortiz, C. (2001). Actores armados, territorios y poblaciones. Análisis politico, 67-75.

Remedios, D. (Julio de 2014). (K. Marín González, Entrevistador) La Macarena.

Santos, B., \& García, M. (2001). El caleidoscopio de las justicias en Colombia. Análisis sociojurídico. Bogotá: Siglo del Hombre.

Theidon, K. (2004). Entre prójimos: el conflicto armado interno y la política de la reconciliación en el Perú. Lima: Instituto de Estudios Peruanos. 
Uprimny, R. (2000). ¿Son posibles los jueces de paz y la justicia comunitaria en contextos violentos?. Pensamiento Jurídico, 53-68.

Uprimny, R. (2005). ¿Justicia transicional sin transición? Bogotá: Centro de Estudios de Derecho, Justicia y Sociedad.

Wolkmer, C. (2003). Pluralismo jurídico: nuevo marco emancipatorio en América Latina. En M. Villegas, \& C. Rodríguez, Derecho y sociedad en América Latina: Un debate sobre los estudios jurídico críticos (págs. 247-259). Bogotá: ILSA.

\section{Nota:}

${ }^{2}$ Este es un Artículo derivado de la investigación "La victimización horizontal y los retos de la justicia transicional en el post conflicto. Estudio de caso Sierra de la Macarena 1990-2014”. El proyecto fue ganador de la convocatoria para el apoyo de trabajos de grado y contó con la financiación de la Facultad de Derecho y Ciencias Políticas de la Universidad de Antioquia. Una versión anterior del texto fue presentada en el III Congreso de Ciencia Politica en Cali. Agradezco a las organizaciones campesinas de ASCATRAGUA, COADYARI, ACATAMU, ASCAL-G, ASOPEPROC y ASOJUNTAS de la Sierra de La Macarena por su disposición para la realización del proyecto. De igual forma agradezco las observaciones realizadas por mi asesor, Nicolás Espinosa. Finalmente he de aclarar que las ideas y juicios que aquí emito solo me comprometen como autora. 